Journal of Social Sciences 7 (3): 343-348, 2011

ISSN 1549-3652

(C) 2011 Science Publications

\title{
Contributions Concerning Muscle Training in Professionnal Volleyball
}

\author{
Niculescu Mugurel, Niculescu Ionela and Amzăr Elena Luminița \\ Department of Physical Education and Sport, University of Piteşti, Pitesti, Romania
}

\begin{abstract}
Problem statement: Complex muscle training, less known to our specialists, has proved that, by complying with all the stages proposed, high level results may be achieved. The performances, weaker and weaker, obtained by the Romanian teams call for measures of optimization and Specific Physical Training (SPT) in accordance to technical -tactical training. Physical training should be individualized and multiplied, under this aspect; we may align to the professional volleyball game. Approach: The purpose of the work was to show ways of optimizing muscle training in a female professional volleyball team, by emphasis on specific muscle training. The work hypotheses: - If we insert in stage plans the individualized muscle training, we shall obtain considerable progress in terms of technical training as well. Results: The combined methods we used had a positive influence on results, on the values of indicators pursued, as opposed to the usual methods. Regardless of the stage in the muscle training, 2 training sessions were conducted a week and the "ball" was present at all times. Conclusion Muscle training shall be performed under the complex type, which we have presented in this work and it shall always be accompanied by technical training as well.
\end{abstract}

Key words: Extensive phase, intensive phase, explosive phase, combinations systems, muscle training, tactical training, Physical training, training sessions, muscle mass, global moves

\section{INTRODUCTION}

The four fundamental stages: Preparatory, precompetition, competition and of transition had their specific objectives (Egger, 1992) both in terms of muscle training and in what concerns technical- tactical training. As mentioned above, each stage has its specific objectives (Egger, 1992):

- Muscular hypertrophy $(10 \times 10$ repetitions-70$80 \%)$, the extensive phase (PP1)-4 weeks (4 microcycles a week)
- Synchronization of mobility units (M.U)-(+ 85\%), the extensive phase $\left(\mathrm{PP}_{2}\right)-3$ weeks $(3$ microcycles a week)

- Accumulating and producing of elastic energy (pliometry)-strength $(\mathrm{F} / \mathrm{V})$, the explosive phase $\left(\mathrm{PP}_{3}\right)$

A. The preparatory stage, (Fig. 1) when emphasis is laid on muscular hypertrophy- is also called the extensive phase (PP1) shall have a duration of 4 weeks and training shall be performed according to the formula $10 \times 10$ with $7080 \%$ of RM.

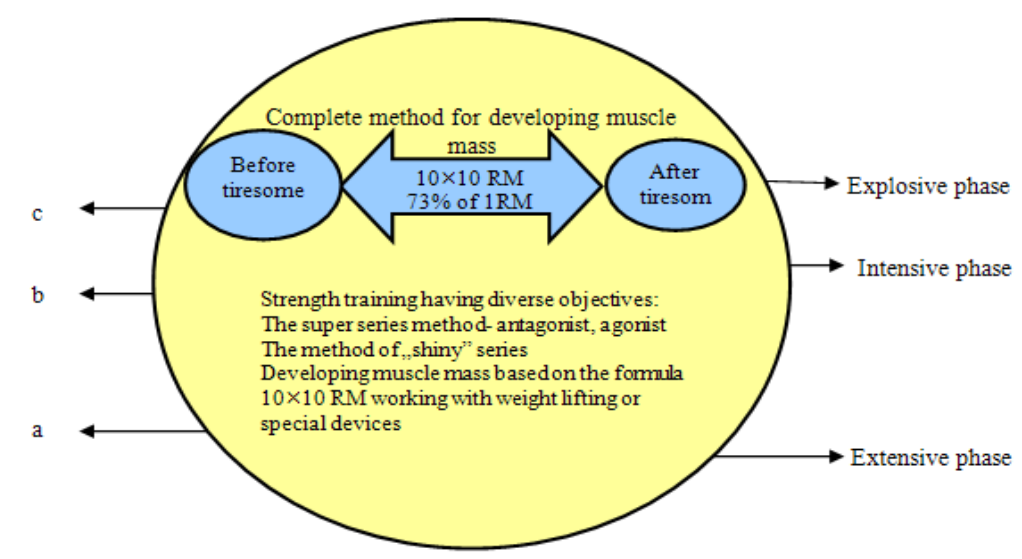

Fig. 1: Strength training, the preparatory stage

Corresponding Author: Niculescu Mugurel, University of Piteşti, Department of Physical Education and Sport, Pitesti, Romania 


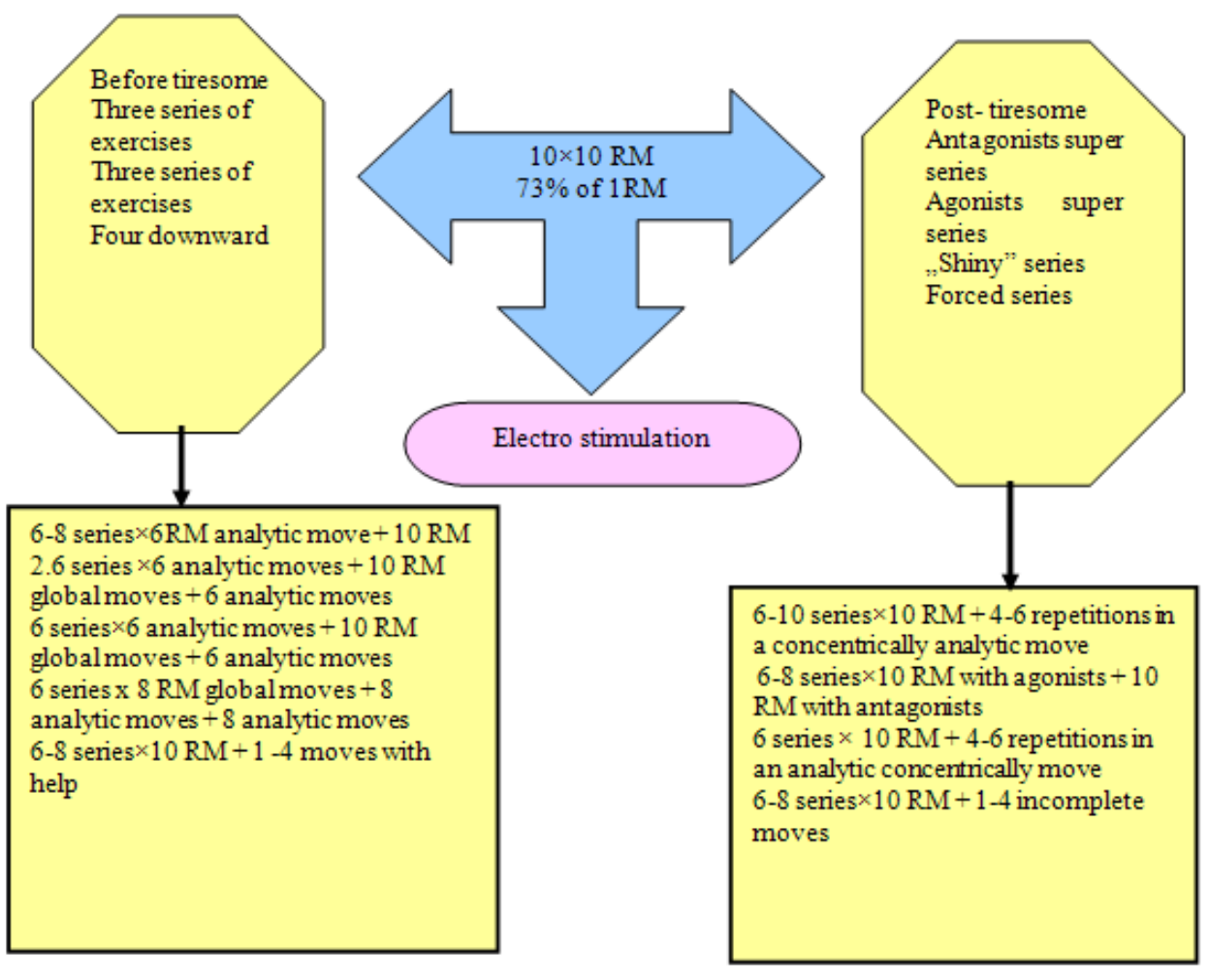

Fig. 2: Complete method for developing muscle mass, (Cometti, 1988)

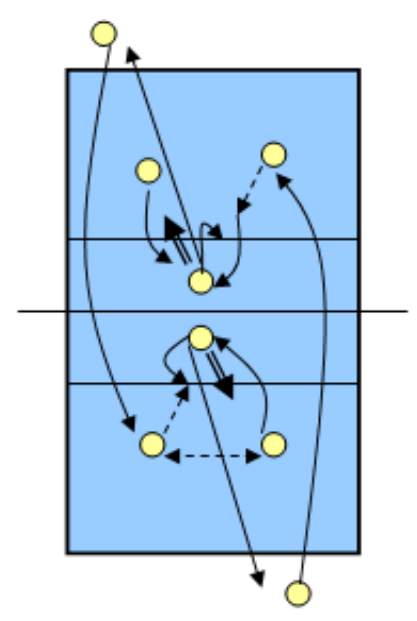

Fig. 3: Receiving the ball from serve in the player from $Z_{3}$ she is performing an attack hit and ball placed alternatively to defense players. 60 executions shall be performed (30 receiving of the ball and 30 serves)

For each example, it is estimated the difficulty in reaching an exhaustion stage, at the tenth repetition. There shall be performed 4 microcycles a week.

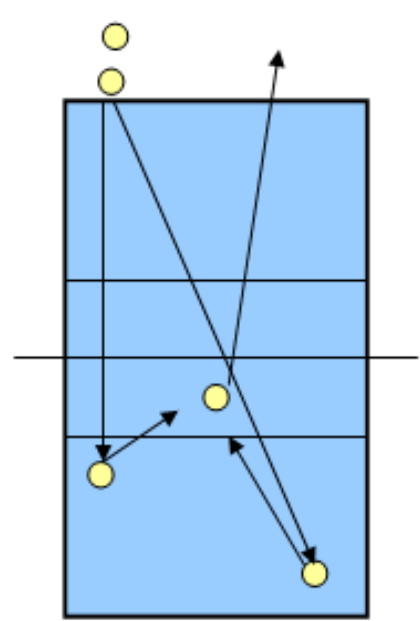

Fig. 4: Long serve in $Z_{1}$ and short serve in $Z 4$ receiving the ball in the player from $Z_{3}$, she catches the ball and passes it to the serving area. 60 executions shall be performed

Strength training, in the preparatory stage always begins with muscle development model as shown in Fig. 2 taken after Commeti1988 


\section{MATERIALS AND METHODS}

It still shows a specific pattern of physical training in volleyball performance. This model is the result of practical experience of the authors in preparing a local team of National League:

- Technical training in this period will be achieved through specific structures, without much intensity, insisting on the correctness of execution. It recommends strengthening the relationship work taking over as shown in Fig. 5-7, the libero player individualized training

- Pre competition stage coincides with the training sessions for synchronizing Mobility Units (MU), which suppose charging of $+85 \%-\mathrm{PP}_{2}$ (intensive phase), it lasts for 3 weeks having 3 microcycles a week

- Competition stage, from a physical point of view is characterized by accumulation training and of producing elastic (pliometry) energy-strength $(\mathrm{F} / \mathrm{V})$ and which is called the explosive phase $\mathrm{PP}_{3}$

- This stage lasts for 3 weeks containing 3 microcycles a week. It is qualitative and it has the role of intra and intermuscular improvement, where explosiveness is developed.

- The transition stage. In this stage it is recommended solely one training of maintenance (strength, mobility) and from a technical point of view, there shall be performed games having reduced levels $(2 \times 2,3 \times 3 ; 4 \times 4)$.

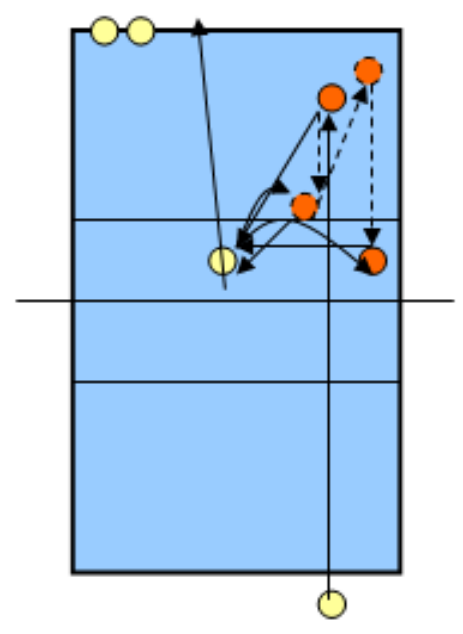

Fig. 5: (a) Libero receiving the ball and defense play with $\mathrm{Z}_{3}$.Dosage: $3 \times 15$ executions

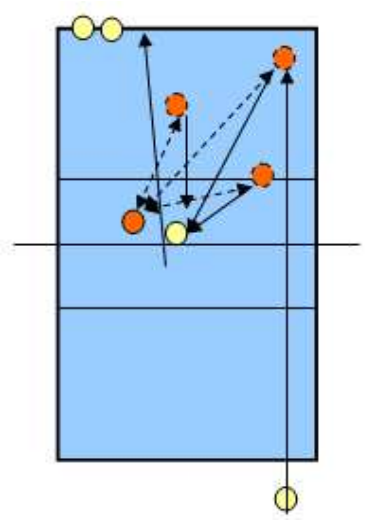

Fig. 5: (b) Libero retreats from the net, receives the ball and the exercise is repeated.Dosage: $3 \times 15$ executions

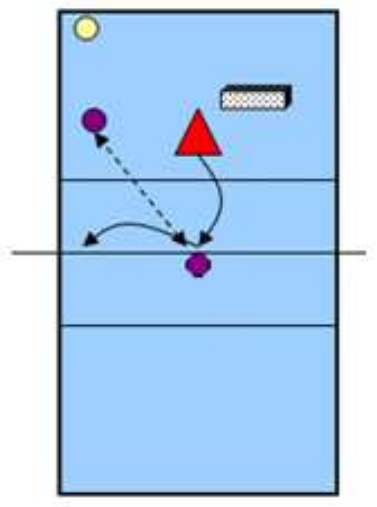

Fig. 6: Game leader shall pass „backward to the movement direction". Dosage: $4 \times 15$ executions

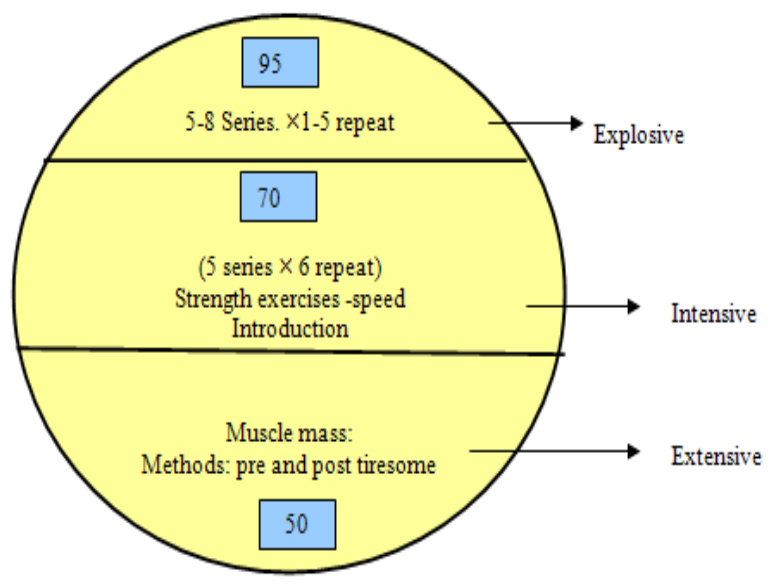

Fig. 7: Pre competition stage 


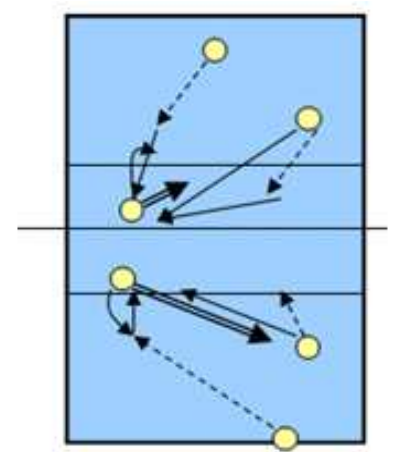

Fig. 8: Receiving the ball by blocking and placing it from the player near the net.Dosage: $4 \times 2$ f for each pair $(5 ;$ Z 6)

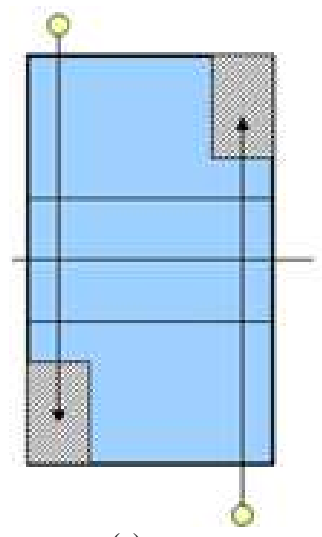

(a)

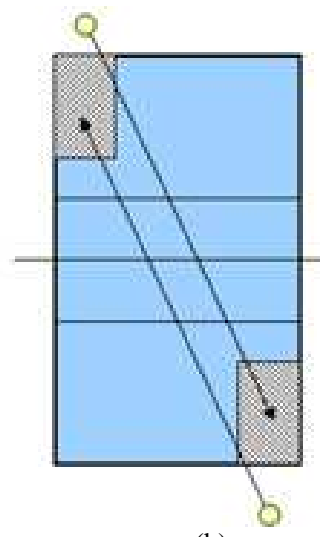

(b)

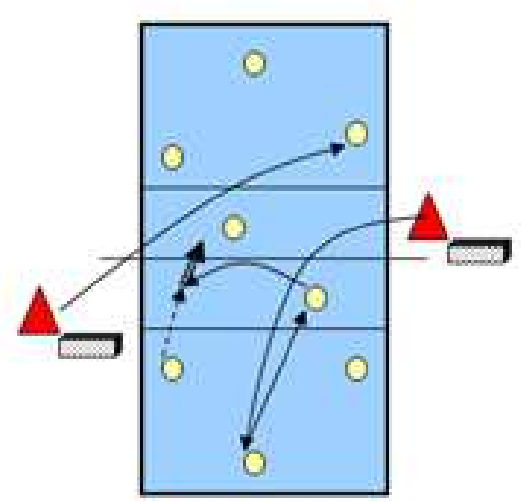

Fig. 10: $4 \times 4$ game by launching alternative ball (to improve defense). Dosage: $4 \mathrm{~s} \times 5^{\prime}$

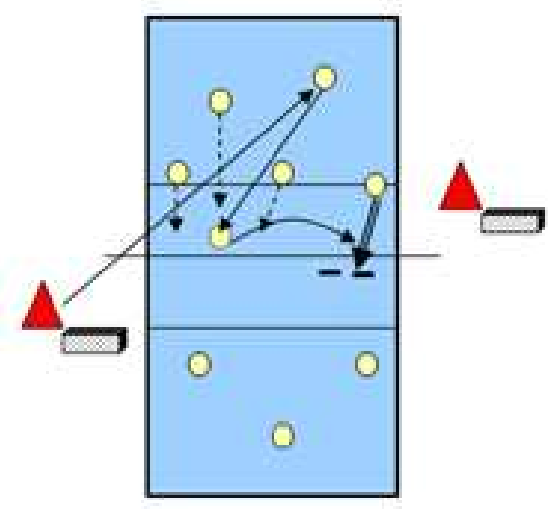

Fig. 11: $5 \times 5$ game with blocking (lines facingeach ) Dosage: $4 \mathrm{~s} \times 5$ '

Fig. 9: Overhand serve in $Z_{1}$ and $Z_{6}$ Dosage: 30 executions for each player

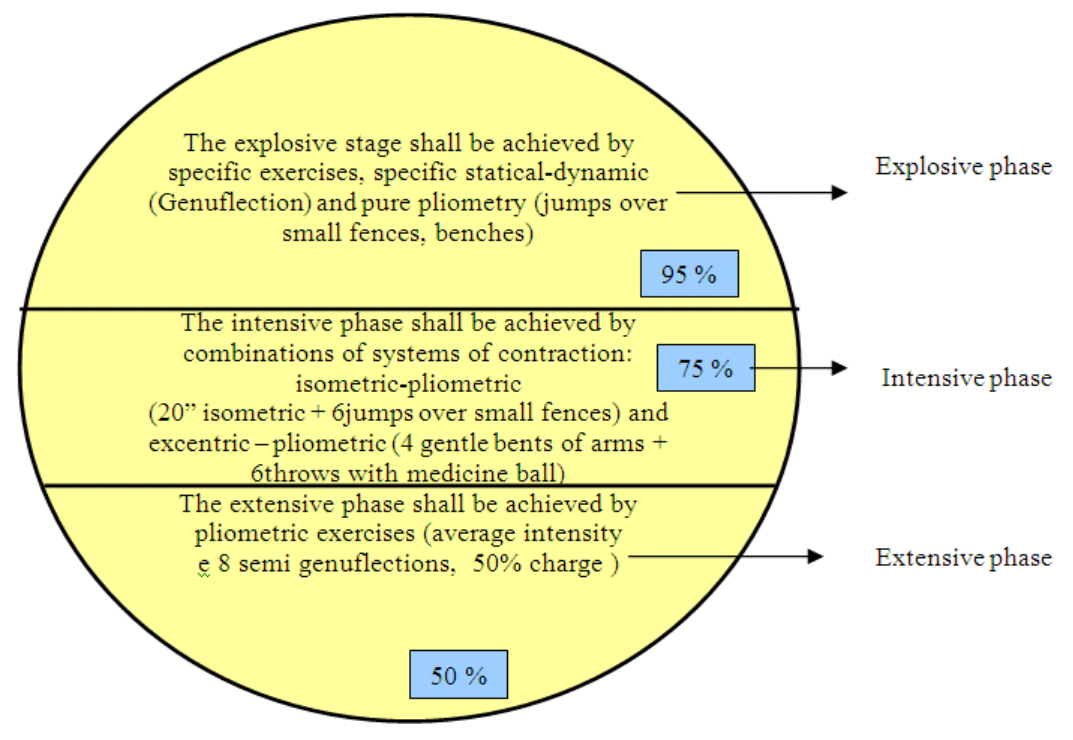

Fig. 12: The competition stage 


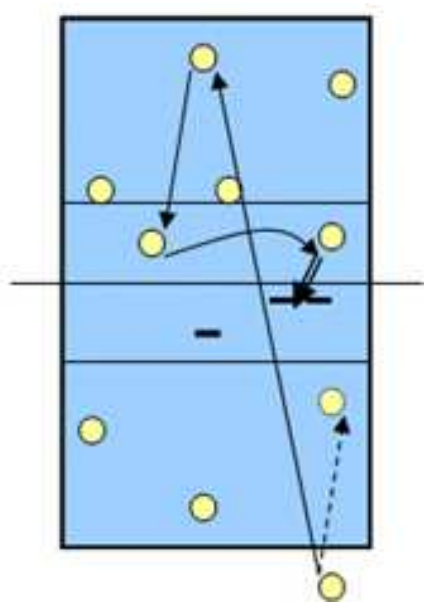

Fig. 13: $6 \times 6$ game with rally scoring $(22-23 ; 21-22)$

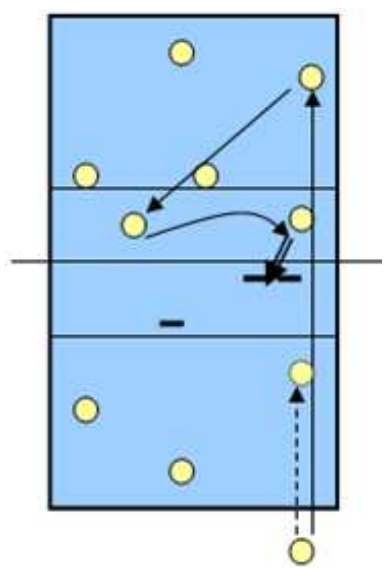

Fig. 14: $6 \times 6$ game- mastering serve on specified areas

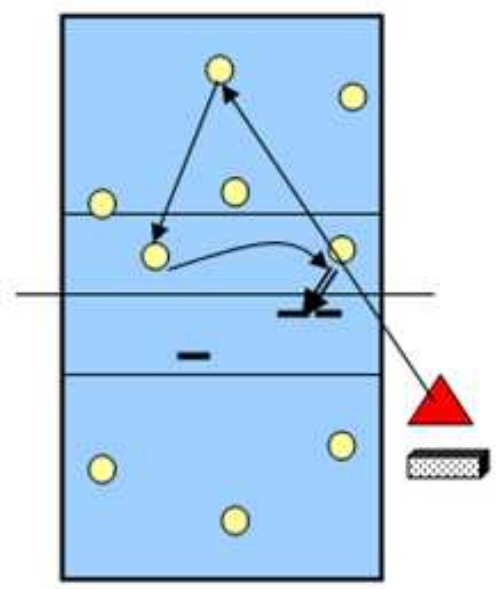

Fig. 15: $6 \times 6$ game with 7 throwed balls, the team scoring the first 4 points wins

\section{RESULTS AND DISCUSSION}

Develop training program stems from the need of unification of content and methodology training volleyball players in the teams' performance, trends and guidelines in line with game preparation and performance encountered in practice today.

Programme (curriculum) is addressed in the education group formed the Sports (sports clubs at school and senior sports clubs).

To reflect the educational priorities of the methodological path of becoming volleyball players, such programming is structured:

- The concept of training volleyball players

- Selection of players

- Samples for verification of technical training tactical and final standards

- The content of the training levels differentiated instruction (A-beginners)

B-advanced I, C-Advanced II D-performance): The curriculum is divided into levels of competitive training, i.e., advanced and performance groups.

Formations of groups, through the stages of training and promotion criteria are those developed by the Romanian Federation of Volleyball and regulations.

Curriculum Framework sets out objectives, reference, training contents and standards of performance to be achieved at the end of each training period, they represent the criteria for promotion to a higher level of training.

Framework objectives are specific to each level of training, directing and creating training content targets specific reference is expressed by the results obtained during that period of training.

Training contents are divided into components of physical training, technical, tactical, theoretical, psychological, intermediate models according to the requirements of the game, scheduled for each level of education.

\section{CONCLUSION}

- Muscle training shall be performed under the complex type, which we have presented in this work and it shall always be accompanied by technical training as well

- The three phases have to always be complied with, mainly the phase for developing muscle mass, synchronization of mobility units and producing elastic energy

- During the competition period, depending on the respective year's calendar, we shall adopt the methodology for muscle training so that the three phases be approached 


\section{REFERENCES}

Alhusseini, N.F., N.A. Belacy, E.M. Kasem and M.M. Allam, 2010. Effect of exercise training on adiponectin receptor expression by physical training. J. Clin. Endocrinol. Metab., 6: 2310-2316. DOI: $10.1210 /$ jc. 2005-. 2556

Bompa, T.O. and G. Haff, 2009, Periodization. The Theory and Methodology of Training. 5th Edn., Human Kinetics, Leeds, ISBN: 0736085475, pp: 411.

Combs, T.P., J.A. Wagner, J. Berger and T. Doebber, 10.3844/ajbbsp.2010.77.83Am. J. Biochem. Biotechnol., 6: 77-83.
Cometti, G., 1988, Les Méthodes Modernes de Musculation. 1st Edn., Université de Bourgogne, ISBN: 2950119417:

Ismail, R., M.R.A. Mansor, M.F.M. Ali, S. Jaafar and N.K. Makhtar, 2010. Biomechanical analysis of ankle force: A case study for instep kicking. Am. J. Applied Sci., 7: 323-330. DOI: 10.3844/ajassp.2010.323.330

View Fultext PDF - The Effects of Fatigue and Chronic Ankle... physical education students (14 males, 16 females) in two groups (15 healthy ... reducing of balance can be practical guideline for training programs and... 10.3844/pisp.2010.22.26 Phys. Int., 1: 22-26.

Weineck, J., 2003, Manuel D'entrainement. 4th Edn., Vigot, Paris, ISBN: 2711412989, pp: 577. 